Original Article

\title{
Not intended, still embarrassed: Social anxiety is related to increased levels of embarrassment in response to unintentional social norm violations
}

\author{
Janna Marie Bas-Hoogendam ${ }^{\mathrm{a}, \mathrm{b}, \mathrm{c}, *, 1}$, Henk van Steenbergen ${ }^{\mathrm{a}, \mathrm{c}}$, Nic J.A. van der Wee ${ }^{\mathrm{b}, \mathrm{c}}$, \\ P. Michiel Westenberg ${ }^{a, c}$ \\ a Institute of Psychology, Leiden University, Wassenaarseweg 52, 2333 AK, Leiden, The Netherlands, The Netherlands \\ ${ }^{\mathrm{b}}$ Department of Psychiatry, Leiden University Medical Center, Albinusdreef 2, 2333 ZA, Leiden, The Netherlands \\ ${ }^{\mathrm{c}}$ Leiden Institute for Brain and Cognition, Leiden, The Netherlands
}

\section{A R T I C L E I N F O}

\section{Article history:}

Received 28 September 2017

Received in revised form 16 February 2018 Accepted 7 March 2018

Available online 30 March 2018

\section{Keywords:}

Anxiety disorders

Social phobia

Social norm violations

Embarrassment

Intentionality

\begin{abstract}
A B S T R A C T
Background: Social anxiety disorder (SAD) is associated with altered social norm (SN) processing: SADpatients rate stories on SN violations as more inappropriate and more embarrassing than healthy participants, with the most prominent effect for stories on unintentional SN violations (i.e. committing a blunder). Until now it's unknown how levels of social anxiety (SA) are related to ratings of SN violations in the general population, in which SA-symptoms are present at a continuum. More insight in this relationship could improve our understanding of the symptom profile of SAD. Therefore, we investigated the relation between ratings of SN violations and SA-levels in the general population.

Methods: Adults and adolescents $(n=87)$ performed the revised Social Norm Processing Task (SNPT-R) and completed self-report questionnaires on social anxiety. Repeated-measures ANCOVAs were used to investigate the effect of SA on the ratings of inappropriateness and embarrassment.

Results: As hypothesized, participants with higher SA-levels rated SN violations as more inappropriate and more embarrassing. Whereas participants with low-to-intermediate SA-levels rated unintentional SN violations as less embarrassing than intentional SN violations, participants with high SA-levels (zscore $S A \geq 1.6$ ) rated unintentional $S N$ violations as equally embarrassing as intentional $S N$ violations. Conclusions: These findings indicate that increased embarrassment for unintentional SN violations is an important characteristic of social anxiety. These high levels of embarrassment are likely related to the debilitating concern of socially-anxious people that their skills and behavior do not meet expectations of others, and to their fear of blundering. This concern might be an important target for future therapeutic interventions.
\end{abstract}

(ㄷ) 2018 Elsevier Masson SAS. All rights reserved.

\section{Introduction}

Social anxiety (SA) is an emotion that is experienced by most people with some regularity. Typically, people want to make a good impression when they are in a social situation, and when committing a blunder in the presence of others, people tend to feel embarrassed or ashamed. However, the experience of social anxiety varies between people, ranging from discomfort in specific social situations

\footnotetext{
* Corresponding author at: Developmental and Educational Psychology, Institute of Psychology, Leiden University, Wassenaarseweg 52, Pieter de la Court Building, room 3.B43, 2333 AK, Leiden, The Netherlands.

E-mail address: j.m.hoogendam@fsw.leidenuniv.nl (J.M. Bas-Hoogendam).

1 https://www.researchgate.net/profile/Janna_Marie_Bas_Hoogendam.
}

for some individuals to an intense fear in almost all social situations for others [1]. At the upper end of 'this continuum of social anxiety' [2] lies social anxiety disorder(SAD), a psychiatric condition which is, according to the Diagnostic and Statistical Manual of Mental Disorders (DSM-5), characterized by an intense fear of being negatively evaluated in social situations [3]. This fear of social-evaluative stimuli [4], which is out of proportion to the actual threat and to the sociocultural context $[5,6]$ leads to the avoidance of social situations and results in significant disturbances in a person's everyday life $[3,7]$. The typical onset of SAD is during childhood or adolescence and several environmental as well as intrinsic factors like genetic influences, biological factors as well as cognitive biases interact in the development of the disorder [8].

Previous studies have indicated that SAD-patients experience disturbances in self-referential processing and have biases 
concerning the opinion of others about them: they have increased self-portrayal concerns [9], for example when it concerns their social rank $[10,11]$ or their own social performance $[12,13]$, they overestimate the negative consequences of their own social blunders [14] and are characterized by negatively biased learning about themselves from social feedback [15]. Furthermore, clinical SAD is associated with an increased belief in negative interpretations of social situations [16] and SAD-patients focus predominantly on potentially embarrassing events when they evaluate themselves in a social context [17]. Such negative self-beliefs, which are already present in adolescents with SAD [18,19], are related to increased negative emotions like fear and anxiety, and induce maladaptive behavioral responses like safety behaviors, which, consecutively, lead to the maintenance of social anxiety $[20,21]$. It has been argued that SAD-patients are 'uniquely and primarily concerned about characteristics of self that they perceive as being deficient or contrary to perceived societal expectations or norms' [22]. According to this view, one of the main concerns of SAD-patients is the fear that they will unintentionally commit an embarrassing behavioral blunder in a social situation [22], which let us to hypothesize that social anxiety is specifically related to the experience of increased embarrassment in reaction to unintentional social norm violations.

This idea was previously examined by investigating the behavioral data of a functional Magnetic Resonance Imaging (fMRI) study using the social norm processing task (SNPT) [23]. In this task, participants read three types of short stories: stories describing neutral social situations, stories on unintentional social norm (SN) transgressions (i.e. committing a blunder) and stories describing intentional SN transgressions (i.e. breaking conventional rules) and they are asked to imagine themselves in the situation described. Subsequently, participants rate the stories on inappropriateness and embarrassment. Thereby, the SNPT enables investigating the effect of intention on these ratings. Blair and colleagues [23] showed that, while SAD-patients had higher selfreported levels of inappropriateness and embarrassment across all conditions, the effect of SAD was most pronounced for unintentional SN violations: adult patients with generalized SAD $(n=16)$ rated these unintentional transgressions as significantly more embarrassing when compared to healthy participants $(n=16)$. Furthermore, the fMRI analyses revealed that reading the unintentional stories evoked increased activation in the ventromedial prefrontal cortex in SAD. This activation was considered to represent increased self-referential processing and was taken to indicate that SAD-patients judge unintentional SN violations as more self-relevant than healthy participants [23].

The results of this study [23], which was the first, and, to the best of our knowledge, the only study to date investigating the difference between processing intentional and unintentional SN violations in SAD, provide important initial evidence that the intention underlying a $\mathrm{SN}$ violation is a determining factor in the experience of embarrassment in social anxiety: although SADpatients reported higher embarrassment for all social situations, they differed most from control participants when they considered unintentional transgressions [23]. However, the sample size of the study was relatively small. In addition, participants performed an 'impersonal' version of the SNPT, in which the stories described behavior of an unknown character like 'Joanna' (cf. [24]), as a result of which it could be questioned whether the ratings reflect the participants' opinion about their own SN violations. Furthermore, it is unknown if the effect of intention on the level of embarrassment also holds for participants with higher SA-levels in the general population.

Here, we investigated the relation between self-reported SA and behavioral ratings of SN violations in a sample of adults and adolescents from the general population $(n=87)$, using the revised
Social Norm Processing Task (SNPT-R) [25]. In the SNPT-R, the three types of stories were written in second-person, in order to let the ratings reflect how participants think about their own SN violations. Data of this sample on the SNPT-R have been published previously [25].

Based on previous work [23], we hypothesized that higher SAlevels within the general population would be predictive of a general effect of SA, reflected by higher ratings of inappropriateness and embarrassment for all stories and of an intention-specific effect of SA, namely an even more pronounced increase in embarrassment ratings for stories on unintentional SN violations. More insight in this relationship could help further unravel mechanisms involved in the etiology and maintenance of social anxiety and may identify potential novel targets for prevention and intervention.

\section{Methods}

\subsection{Participants}

Participants were adults and adolescents from the general population ( $n=87$; age range $12.5-32.6 \mathrm{y}$ ), the same as those described previously [25]; details of the inclusion procedure are described in the Supplemental Methods. They had Dutch as their first language and were free of past and present psychopathology as assessed by a self-report questionnaire. After explanation of the procedure, all participants (and in case of minors below 18 years of age, both parents) signed informed consent according to the Declaration of Helsinki. The Psychology Research Ethics Committee of Leiden University approved the experiment.

\subsection{Social norm processing task}

Participants performed the revised Social Norm Processing Task (SNPT-R), described in detail previously [25]. The SNPT-R consists of two phases.

In the first phase, participants read three types of short stories: stories on situations in which no social norm (SN) was violated (neutral condition; for example: 'You are baking an apple pie with your friends. You use the amount of sugar the recipe calls for'), stories describing unintentional SN violations (unintentional condition; 'You are baking an apple pie with your friends. You use salt instead of sugar without realizing') and stories outlining intentional SN violations (intentional condition; 'You are baking an apple pie with your friends. You use salt instead of sugar as a joke'). Stories in the unintentional and intentional condition described relatively innocent violations of conventional social norms, in situations where at least one other person was present. The intentional and unintentional stories differed only in the intention of the actor, while the actual result of the violation (for example: a distasteful cake) was kept as much as possible the same. Stories were written in second-person and participants were instructed to imagine themselves in the situations, in order to maximize their personal involvement (cf. [26]). Therefore, four age- and genderspecific versions of the task were used: for boys $<18$ years, girls $<18$ years, men $\geq 18$ years and women $\geq 18$ years. The task consisted of 78 stories and a full list of stories is provided in Bas-Hoogendam et al. [25]. We refer the reader to this work and to the Open Science Framework (OSF)-project [dataset] [27] for more details on task parameters and scripts for task presentation.

Secondly, there was an unannounced rating-phase, in which participants were asked to rate all stories on a 5-point Likert scale on embarrassment (from 1, not embarrassing at all, to 5, extremely embarrassing) and inappropriateness (from 1, not inappropriate at all, to 5 , extremely inappropriate). These ratings were the outputmeasures used in this study. 
Both phases of the SNPT-R were presented using E-Prime software (version 2.0.10, Psychology Software Tools; available at osf.io/pt4qt [dataset]) [27].

\subsection{Self-report questionnaires}

As there exists, to the best of our knowledge, no instrument which is suitable to reliably assess the level of social anxiety in both adults and adolescents, two questionnaires were used to determine social anxiety: depending on their age, participants completed the self-report version of the Liebowitz Social Anxiety Scale (LSAS) [28] or the Social Anxiety Scale for Adolescents (SASA) [29]. The LSAS is a questionnaire for adults measuring fear in and avoidance of situations that are likely to elicit social anxiety $[28,30]$. The SAS-A [29] measures social anxiety in adolescents, with satisfactory levels of internal consistency [31].

Boys and girls did not differ in self-reported SA as measured with the SAS-A (independent-samples $t$-test: $t(27)=-0.41, p=0.69$ ), while women reported significantly more SA-symptoms compared to men, as measured with the LSAS $(t(56)=-3.24, p=0.002$ ) (cf. [ 32-36]) (Table 1). Because we aimed to investigate the relation between self-reported SA and ratings on the SNPT-R within each group of participants (boys $<18$ years; girls $<18$ years; men $\geq 18$ years; women $\geq 18$ years), rather than over the whole sample (an analysis which could be influenced by age- and gender differences), we normalized the scores on the LSAS and SAS-A within each group and used the z-scores (SA-Z) for further analyses. The validity of this measure was established by additional analyses, separate for the adolescent and adult sample, using the original LSAS and SAS-A scores; in these analyses, we observed in general the same pattern of results as described in the Results-section. Furthermore, exploratory analyses indicated no significant interactions between SA-Z, agegroup (adult vs. adolescents) and behavioral ratings.

After z-standardizing the scores on the LSAS and SAS-A within each group, one participant (male) was considered an outlier (SA$\mathrm{Z}=3.27$ ) and removed from subsequent analyses (remaining sample: $n=86$ ).

\subsection{Procedure}

The experiment took place at the Faculty of Social and Behavioural Sciences, Leiden University, the Netherlands (adult participants) and at a secondary school in the Netherlands (adolescent participants). Participants performed both phases of the SNPT-R and the self-report questionnaires on a laptop in a quiet environment.

\subsection{Data analysis}

Statistical analyses of the ratings of embarrassment and inappropriateness for the SNPT-R stories were performed using IBM SPSS Statistics for Mac (Version 24.0). The relationships between behavioral ratings of inappropriateness and embarrassment and social anxiety were investigated using repeatedmeasures ANCOVAs with condition (intentional; unintentional; neutral) as within-subjects factor and SA-Z as covariate. Significant effects of condition were further investigated using pairedsamples $t$-tests; significant effects of SA-Z were examined using separate regression analyses for each condition (independent variable: SA-Z; dependent variables: ratings), while significant interactions between condition and SA-Z were explored using regression analyses with the difference scores of the ratings as dependent variables (e.g., $\Delta$ Intentional_unintentional = intentional score minus unintentional score). For reasons of completeness and in line with the analyses reported previously [25], we repeated the above described ANCOVAs with group (based on the four versions of the task; group 1: boys $<18$ years of age; group 2: girls $<18$ years of age; group 3 : men $\geq 18$ years of age; group 4 ; women $\geq 18$ years of age) as additional between-subjects factor. Results of these analyses are summarized in Table S1 and Table S2 and discussed in the Supplemental Results.

For all analyses, significance level was set at $\mathrm{p} \leq 0.05$; Greenhouse-Geisser correction was used when the assumption of sphericity was violated.

\section{Results}

\subsection{Participants}

Characteristics of the participants, divided into groups based on the age- and genderspecific versions of the SNPT-R, are summarized in Table 1 . Data are also available at osf.io/j58yc/[dataset] [37]. Using literature-based cutoff scores, 8 adults (14\% of the adult sample; LSAS score $\geq 60$ [38]) and 2 adolescents (7\% of the adolescent sample; SAS-A score $\geq 50$ [39]) met the criteria for generalized SAD.

\subsection{Relationship between ratings and self-reported social anxiety}

Ratings of inappropriateness and embarrassment on the SNPT$\mathrm{R}$ are summarized in Table 2; for group-specific ratings, we refer the reader to [25].

Table 1

Characteristics participants.

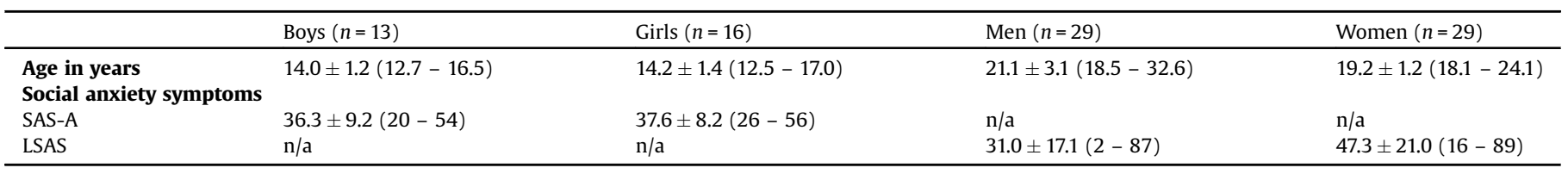

Values are expressed as mean $\pm \mathrm{SD}$ (range).

LSAS: Liebowitz Social Anxiety Scale [28]; SAS-A: Social Anxiety Scale for Adolescents [29]; n/a: not applicable

Table 2

Ratings of embarrassment and inappropriateness on the SNPT- R.

\begin{tabular}{|c|c|c|c|c|c|c|}
\hline & \multicolumn{3}{|c|}{ Inappropriateness } & \multicolumn{3}{|c|}{ Embarrassment } \\
\hline & Intentional & Unintentional & Neutral & Intentional & Unintentional & Neutral \\
\hline Total sample $(n=86)$ & $4.42 \pm 0.36$ & $2.93 \pm 0.51$ & $1.29 \pm 0.20$ & $3.83 \pm 0.67$ & $3.50 \pm 0.56$ & $1.25 \pm 0.21$ \\
\hline
\end{tabular}

Data are presented as means \pm SD. 

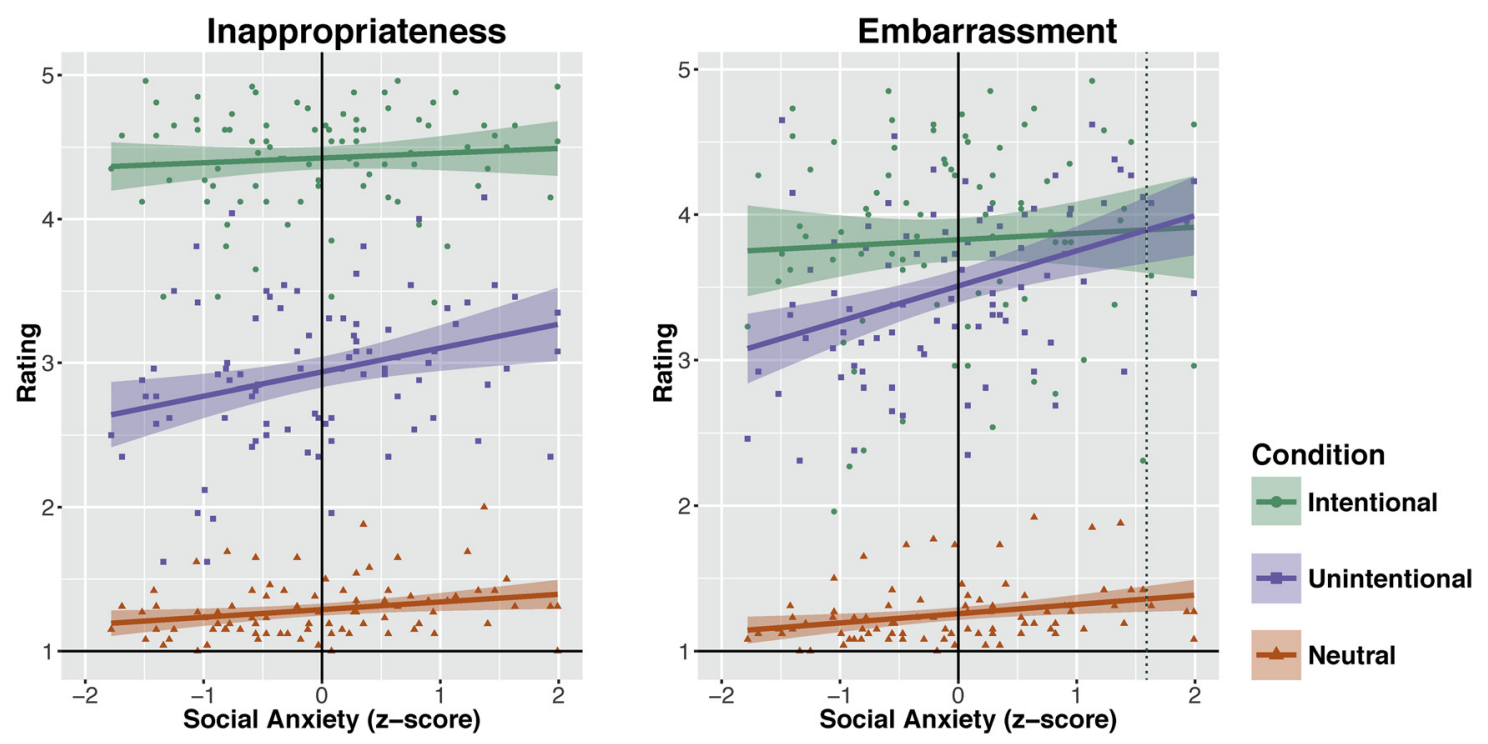

Fig. 1. Relationships between social anxiety (z-standardized) and ratings on the SNPT-R.

Shaded areas represent $95 \%$ confidence intervals (Colour online).

\subsubsection{Inappropriateness}

A repeated-measures ANCOVA (condition $x$ SA-Z) on inappropriateness ratings indicated a main effect of condition $(F(1.8$, 149.5) $=2230.9, \mathrm{p}<0.001$, partial $\eta^{2}=0.97$ ), a main effect of SA-Z $\left(F(1,84)=7.1, p=0.009\right.$, partial $\left.\eta^{2}=0.08\right)$, and an interaction between condition and SA-Z $(F(1.8,149.5)=3.9, p=0.026$, partial $\left.\eta^{2}=0.05\right)$. Paired-samples $t$-tests revealed that intentional stories were rated more inappropriate than unintentional stories $(\mathrm{t}$ $(85)=27.4, \mathrm{p}<0.001)$ and unintentional stories as more inappropriate than neutral stories $(\mathrm{t}(85)=33.6, \mathrm{p}<0.001)$, as reported previously [25]. As illustrated in Fig. 1 (left panel), subsequent regression analyses revealed positive relationships between $\mathrm{SA}-\mathrm{Z}$ and ratings of inappropriateness in the unintentional $(\beta=0.30$, $\mathrm{p}=0.005$; $95 \%$ confidence interval $(\mathrm{CI}): 0.10-0.55)$ and neutral condition $(\beta=0.25, p=0.020 ; 95 \% \mathrm{CI}$ : $0.04-0.50)$, but not in the intentional condition $(\beta=0.085, n s ; 95 \% \mathrm{CI}$ : $-0.14-0.33)$. The interaction between $\mathrm{SA}-\mathrm{Z}$ and condition was further investigated using regression analyses on difference scores. Results showed that SA-Z was positively related to $\Delta$ Unintentional_intentional $(\beta=0.243, \quad p=0.024 ; \quad 95 \% \quad C I: 0.04 \quad-0.49)$ and to $\Delta$ Unintentional_neutral $(\beta=0.23, \mathrm{p}=0.033 ; 95 \% \mathrm{Cl}: 0.20-0.48)$, but not related to $\Delta$ Intentional_neutral $(\beta=-0.05$, ns; $95 \% \mathrm{CI}$ : $-0.29-0.18$ ). These findings indicate that the slope of the regression line for the relationship between SA-Z and inappropriateness in the unintentional condition is significantly steeper when compared to the slopes of the regression lines for the relationships between $S A-Z$ and inappropriateness in the intentional and neutral condition.

\subsubsection{Embarrassment}

A repeated-measures ANCOVA on the ratings of embarrassment showed a main effect of condition $(F(1.8,151.0)=909.9, p<0.001$, partial $\left.\eta^{2}=0.92\right)$, a main effect of $\operatorname{SA}-Z(F(1,84)=7.4, p=0.008$, partial $\left.\eta^{2}=0.08\right)$, and an interaction between condition and SA-Z $\left(F(1.8,151.0)=4.7, p=0.013\right.$, partial $\left.\eta^{2}=0.05\right)$. Intentional stories were rated as more embarrassing than unintentional stories $(\mathrm{t}$ $(85)=4.5, \mathrm{p}<0.001)$ and unintentional stories as more embarrassing than neutral stories $(\mathrm{t}(85)=39.9, \mathrm{p}<0.001)$ [25]. Regression analyses revealed significant positive relationships between $S A-Z$ and embarrassment in the unintentional condition $(\beta=0.40$, $\mathrm{p}<0.001 ; 95 \% \mathrm{CI}: 0.22-0.65)$ and the neutral condition ( $\beta=0.28, p=0.008 ; 95 \% C I: 0.08-0.53$ ), but not between SA-Z and embarrassment in the intentional condition ( $\beta=0.06$, ns; $95 \%$ CI: $-0.17-0.30$ ) (Fig. 1, right panel). The interaction between SA-Z and condition was further investigated using regression analyses on difference scores. Results showed a significant positive relationship between $\mathrm{SA}-\mathrm{Z}$ and $\Delta$ Unintentional_intentional ( $\beta=0.28, p=0.01 ; 95 \% \mathrm{CI}: 0.07-0.53)$, a positive relationship with $\Delta$ Unintentional_neutral $(\beta=0.32, \mathrm{p}=0.003 ; 95 \% \mathrm{CI}: 0.12-0.57)$, but no relationship between SA_Z and $\Delta$ Intentional_neutral ( $\beta=-0.03$, ns; 95\% CI: $-0.27-0.20$ ). Again, these findings indicate that the effect of SA-Z is most pronounced (i.e., steepest slope) on the embarrassment ratings in the unintentional condition. Interestingly, the regression lines depicting the relationships between SA-Z and embarrassment on the intentional and unintentional condition intersect at intermediate-to-high SAlevels ( $S A-Z=1.6$; Fig. 1 , right panel): while individuals with low SA-levels give lower embarrassment scores for unintentional versus intentional SN transgressions, this effect disappears with increasing levels of social anxiety and is no longer significant at high SA-levels in our sample.

\section{Discussion}

We investigated the relationship between self-reported levels of social anxiety (SA) and behavioral ratings on the revised Social Norm Processing Task (SNPT-R) in adults and adolescents from the general population. Previous research showed that patients with social anxiety disorder (SAD) rated all SNPT-stories as significantly more inappropriate and more embarrassing compared to healthy participants, with the most noticeable effect for the unintentional condition [23]. These findings support the hypothesis proposed by Moscovitch [22] that one of the main concerns of SAD-patients is the fear that they will unintentionally commit an embarrassing behavioral blunder in a social situation. Building upon this work, we predicted a general effect of SA, namely, that higher SA-levels in the general population would be associated with higher ratings of inappropriateness and embarrassment. Furthermore, we expected to find an intention-specific effect of SA, reflected by a more pronounced effect of SA on embarrassment ratings for stories on unintentional $\mathrm{SN}$ violations.

These hypotheses were confirmed: overall, participants with higher SA-levels rated the stories as more inappropriate and more embarrassing (Fig. 1), while subsequent regression analyses 
revealed how this general effect of SA was related to the different conditions of the inappropriateness and embarrassment ratings. In the intentional condition, inappropriateness and embarrassment ratings were unrelated to SA, suggesting that SA did not influence people's basic judgment of SN violations: breaking conventional rules is simply considered 'not done' and evokes embarrassment independent of the level of SA. However, SA-levels were positively related to inappropriateness and embarrassment in the neutral condition, which might reflect the general tendency of socially-anxious individuals to feel uncomfortable in social situations [1]. The strongest positive relationships were present between SA-levels and ratings of inappropriateness and embarrassment in the unintentional condition. Importantly, we found an intention-specific effect of SA for embarrassment when comparing the unintentional and intentional conditions. While participants with low-to-intermediate SA-levels rated stories on unintentional SN violations as less embarrassing than stories describing intentional SN violations, participants with high SA-levels ( $z$ score $S A \geq 1.6$ ) rated unintentional $S N$ violations as equally embarrassing as intentional SN violations (Fig. 1, right panel). In other words, participants with lower SA-levels distinguish between breaking conventional rules and committing a blunder in their embarrassment ratings: they take the intention underlying the transgression into account and report less embarrassment when the action was unintentional. However, participants with higher SA-levels do not make this distinction. Note that this intention-specific effect of SA was not found for inappropriateness: individuals with higher SA-levels did still distinguish between intentional and unintentional $\mathrm{SN}$ violations with respect to inappropriateness.

These findings hint at a dissimilarity in the cognitive and affective evaluation of SN violations: at the cognitive level (evaluation of inappropriateness), individuals with high SA-levels are not all that different from those with low SA-levels; at the affective level (evaluation of embarrassment), however, they fail to make the distinction between intentional and unintentional SN violations. This increased experience of embarrassment could contribute to the development and maintenance of SAD, as embarrassment is a self-conscious emotion with two sides: although it is a prosocial emotion signaling the recognition of misbehavior and holding the promise that the mistake will not happen again, it also represents negative self-evaluations [40-42]. When embarrassment occurs too often and too intensely, these negative self-evaluations can lead to an overestimation of the extent to which a misstep is important to others, to misplaced and needless concerns about other people's judgment, and to timid, passive behavior [43] - a tendency that characterizes sociallyanxious people.

The results reported here extend those of Blair and colleagues [23], by showing that the aberrant behavioral response to unintentional SN violations observed in SAD-patients is also present in participants from the general population with high SA-levels. Furthermore, our finding of increased embarrassment for unintentional $\mathrm{SN}$ violations is in line with previous work, which indicated that both SAD-patients as well as participants with high SA-levels overestimate the negative consequences of unintentional social blunders [14,44]. In addition, our results link to the idea that both negative interpretation biases as well as disordered self-referential processing, at the cognitive and neural level, are important characteristics of SA [17,45-55]. Furthermore, studies have indicated that SA is associated with increased levels of perfectionism, especially with heightened concerns over making mistakes [56-59] and with high levels of self-criticism [60]. Together with these observations, our results support the idea that participants with high SA-levels are characterized by a fear of blundering in a social situation and by a strong concern that their skills and behavior do not meet perceived societal expectations [22]. Thereby, our findings contribute to understanding the symptom profile in at-risk populations and in SAD-patients and could aid in improving preventive and therapeutic interventions for this disorder. Cognitive behavioral therapy could, for example, challenge the concern of patients that their self-characteristics are deficient and do not satisfy societal norms and help patients to realize that the consequences of unintentional blunders are probably not as bad as they consider them to be [22]. This is of importance, given that the increased experience of embarrassment leads to maladaptive coping strategies like avoidance and safety behaviors, which are maintaining factors of SAD [4,21,61].

A limitation of the present study is the relatively small sample size, especially given the fact that participants were divided into four groups based on the versions of the SNPT-R (versions for respectively boys, girls, men and women). Especially the number of included adolescents is limited, as a result of which we were unable to investigate whether age influences the relationship between SA and embarrassment. Given that adolescence is a critical time period for the onset of SAD [62], a longitudinal study on a large sample of adolescents could give more insight in the role of embarrassment in the development of SAD. In addition, the presence of past and present psychopathology in the sample was only assessed by self-report, which could lead to an underestimation of psychopathology. For example, SAD-patients are often underestimating their condition and refrain from consulting their general practitioner, which may lead to underdiagnosis [63]. Actually, ten participants of the current sample met the criteria for generalized SAD as based on the cutoff scores for the LSAS and SASA [38,39], but due to the lack of structured clinical interview, these diagnoses could not be confirmed by a clinician.

Furthermore, we did not acquire neuroimaging data, thus we could not relate our data to neural activity (cf. [23]). Future imaging studies could investigate whether SA-levels alter activation in brain regions involved in $\mathrm{SN}$ processing. Because increased activation in the ventromedial prefrontal cortex in SAD-patients in response to unintentional SN violations has been reported [23], we hypothesize that higher SA-levels are related to differential activation within this region. Such an experiment could provide more insight in the neural basis of the altered SN processing associated with high SA-levels. Furthermore, family-studies involving SAD-patients as well as their relatives could investigate whether altered SN processing and the associated neural pattern are heritable characteristics, representing an endophenotype of SAD [64,65]. This could enhance our understanding of the familial component of SAD.

\section{Conclusions}

To conclude, the data presented here show that high levels of social anxiety in the general population are associated with increased embarrassment for unintentional social norm violations. Although the generalizability of our results might be limited by the relatively small sample size, these findings provide more insight in the core fear of socially-anxious individuals and offer clues for therapeutic interventions.

\section{Disclosure statement}

No potential conflict of interest was reported by the authors.

\section{Funding sources}

Janna Marie Bas-Hoogendam is funded by the Leiden University Research Profile 'Health, Prevention and the Human Life Cycle'. The 
funding source had no involvement in writing this paper nor in the decision to submit this work for publication.

\section{Acknowledgement}

We gratefully thank Tanja Kreuk who was involved in designing the study and data acquisition as part of her research master thesis project.

\section{Appendix A. Supplementary data}

Supplementary data associated with this article can be found, in the online version, at https://doi.org/10.1016/j.eurpsy.2018.03.002.

\section{References}

[1] Miskovic V., Schmidt LA. Social fearfulness in the human brain. Neurosci Biobehav Rev 2012;36:459-78, doi:http://dx.doi.org/10.1016/j. neubiorev.2011.08.002

[2] Rapee RM, Spence SH. The etiology of social phobia: empirical evidence and an initial model. Clin Psychol Rev 2004;24:737-67, doi:http://dx.doi.org/10.1016/ j.cpr.2004.06.004.

[3] American Psychiatric Association. Diagnostic and statistical manual of mental disorders. 5th ed. (dsm-5) 2013.

[4] Wong QJJ, Rapee RM. The aetiology and maintenance of social anxiety disorder: a synthesis of complimentary theoretical models and formulation of a new integrated model. J Affect Disord 2016;203:84-100, doi:http://dx.doi. org/10.1016/j.jad.2016.05.069.

[5] Leichsenring F, Leweke F. Social anxiety disorder. New Engl J Med 2017;376:2255-64, doi:http://dx.doi.org/10.1056/NEJMcp1614701.

[6] Heimberg RG, Hofmann SG, Liebowitz MR, Schneier FR, Smits JA], Stein MB, et al. Social anxiety disorder in DSM-5. Depress Anxiety 2014;31:472-9, doi: http://dx.doi.org/10.1002/da.22231.

[7] Stein MB, Stein DJ. Social anxiety disorder. Lancet 2008;371:1115-25, doi: http://dx.doi.org/10.1016/S0140-6736(08)60488-2.

[8] Spence SH, Rapee RM. The etiology of social anxiety disorder: an evidencebased model. Behav Res Ther 2016;86:50-67, doi:http://dx.doi.org/10.1016/j. brat.2016.06.007.

[9] Moscovitch DA, Rowa K, Paulitzki JR, Ierullo MD, Chiang B, Antony MM, et al. Self-portrayal concerns and their relation to safety behaviors and negative affect in social anxiety disorder. Behav Res Ther 2013;51:476-86, doi:http://dx. doi.org/10.1016/j.brat.2013.05.002.

[10] Berger U, Keshet H, Gilboa-Schechtman E. Self-evaluations in social anxiety: the combined role of explicit and implicit social-rank. Pers Individ Dif 2017;104:368-73, doi:http://dx.doi.org/10.1016/j.paid.2016.08.023.

[11] Gilboa-Schechtman E, Keshet H, Livne T, Berger U, Zabag R, Hermesh H, et al. Explicit and implicit self-evaluations in social anxiety disorder. J Abnorm Psychol 2017;126:285-90, doi:http://dx.doi.org/10.1037/abn0000261.

[12] Gavric D, Moscovitch DA, Rowa K, McCabe RE. Post-event processing in social anxiety disorder: examining the mediating roles of positive metacognitive beliefs and perceptions of performance. Behav Res Ther 2017;91:1-12, doi: http://dx.doi.org/10.1016/j.brat.2017.01.002.

[13] Glazier BL, Alden LE. Social anxiety and biased recall of positive information: it's not the content, it's the valence. Behav Ther 2017;48:533-43, doi:http://dx. doi.org/10.1016/j.beth.2016.08.001.

[14] Moscovitch DA, Waechter S, Bielak T, Rowa K, McCabe RE. Out of the shadows and into the spotlight: social blunders fuel fear of self-exposure in social anxiety disorder. J Anxiety Disord 2015;34:24-32, doi:http://dx.doi.org/ 10.1016/j.janxdis.2015.06.004.

[15] Koban L, Schneider R, Ashar YK, Andrews-Hanna JR, Landy L, Moscovitch DA, et al. Social anxiety is characterized by biased learning about performance and the self. Emotion 2017, doi:http://dx.doi.org/10.1037/emo0000296.

[16] Loscalzo Y, Giannini M, Miers AC. Social anxiety and interpretation bias: examining clinical and subclinical components in adolescents. Child Adolesc Ment Health 2017, doi:http://dx.doi.org/10.1111/camh.12221.

[17] Blair KS, Blair RJR. A cognitive neuroscience approach to generalized anxiety disorder and social phobia. Emot Rev 2012;4:133-8, doi:http://dx.doi.org/ 10.1177/1754073911430251.

[18] Schreiber F, Steil R. Haunting self-images? The role of negative self-images in adolescent social anxiety disorder. J Behav Ther Exp Psychiatry 2013;44:15864, doi:http://dx.doi.org/10.1016/j.jbtep.2012.10.003.

[19] Blöte AW, Miers AC, Heyne DA, Clark DM, Westenberg PM. The relation between social anxiety and audience perception: examining clark and wells' 1995 model among adolescents. Behav Cogn Psychother 2014;42:555-67, doi: http://dx.doi.org/10.1017/S1352465813000271.

[20] Goldin PR, Manber-Ball T, Werner K, Heimberg R, Gross JJ. Neural mechanisms of cognitive reappraisal of negative self-beliefs in social anxiety disorder. Biol Psychiatry 2009;66:1091-9, doi:http://dx.doi.org/10.1016/j. biopsych.2009.07.014.
[21] Piccirillo ML, Dryman MT, Heimberg RG. Safety behaviors in adults with social anxiety: review and future directions. Behav Ther 2016;47:675-87, doi:http:// dx.doi.org/10.1016/J.BETH.2015.11.005.

[22] Moscovitch DA. What is the core fear in social phobia? A new model to facilitate individualized case conceptualization and treatment. Cogn Behav Pract 2009;16:123-34, doi:http://dx.doi.org/10.1016/j.cbpra.2008.04.002.

[23] Blair KS, Geraci M, Hollon N, Otero M, DeVido J, Majestic C, et al. Social norm processing in adult social phobia: a typically increased ventromedial frontal cortex responsiveness to unintentional (embarrassing) transgressions. Am J Psychiatry 2010;167:1526-32, doi:http://dx.doi.org/10.1176/appi. ajp.2010.09121797.

[24] Berthoz S, Armony JL, Blair RJR, Dolan RJ. An fMRI study of intentional and unintentional (embarrassing) violations of social norms. Brain 2002;125:1696-708, doi:http://dx.doi.org/10.1093/brain/awf190.

[25] Bas-Hoogendam JM, van Steenbergen H, Kreuk T, van der Wee NJA Westenberg PM. How embarrassing! The behavioral and neural correlates of processing social norm violations. PLoS One 2017;12:e0176326, doi:http:/ dx.doi.org/10.1371/journal.pone.0176326.

[26] Finger EC, Marsh AA, Kamel N, Mitchell DGV, Blair JR. Caught in the act: the impact of audience on the neural response to morally and socially inappropriate behavior. Neuroimage 2006;33:414-21, doi:http://dx.doi.org/ 10.1016/j.neuroimage.2006.06.011

[27] Bas-Hoogendam JM, van Steenbergen $H$, Kreuk $T$, van der Wee NJA, Westenberg PM. Revised social norm processing task (SNPT-R). Database Open Sci Framew 2017, doi:http://dx.doi.org/10.17605/OSF.IO/M8R76.

[28] Heimberg RG, Horner KJ, Juster HR, Safren SA, Brown EJ, Schneier FR, et al Psychometric properties of the liebowitz social anxiety scale. Psychol Med 1999;29:199-212, doi:http://dx.doi.org/10.1017/S0033291798007879.

[29] La Greca AM, Lopez N. Social anxiety among adolescents: linkages with peer relations and friendships. J Abnorm Child Psychol 1998;26:83-94, doi:http:// dx.doi.org/10.1023/A:1022684520514.

[30] Fresco DM, Coles ME, Heimberg RG, Liebowitz MR, Hami S, Stein MB, et al. The Liebowitz Social Anxiety Scale: a comparison of the psychometric properties of self-report and clinician-administered formats. Psychol Med 2001;31:1025-35, doi:http://dx.doi.org/10.1017/S0033291701004056.

[31] Miers AC, Blöte AW, de Rooij M, Bokhorst CL, Westenberg PM. Trajectories of social anxiety during adolescence and relations with cognition, social competence, and temperament. J Abnorm Child Psychol 2013;41:97-110, doi: http://dx.doi.org/10.1007/s10802-012-9651-6.

[32] Turk CL, Heimberg RG, Orsillo SM, Holt CS, Gitow A, Street LL, et al. An investigation of gender differences in social phobia. J Anxiety Disord 1998;12:209-23, doi:http://dx.doi.org/10.1016/S0887-6185(98)00010-3.

[33] Duke D, Krishnan M, Faith M, Storch EA. The psychometric properties of the brief fear of negative evaluation scale. J Anxiety Disord 2006;20:807-17, doi: http://dx.doi.org/10.1016/j.janxdis.2005.11.002.

[34] Carleton RN, Collimore KC, Asmundson GJG. Social anxiety and fear of negative evaluation: construct validity of the BFNE-II. J Anxiety Disord 2007;21:131-41, doi:http://dx.doi.org/10.1016/j.janxdis.2006.03.010.

[35] Asher M, Asnaani A, Aderka IM. Gender differences in social anxiety disorder: review. Clin Psychol Rev 2017;56:1-12, doi:http://dx.doi.org/10.1016/j. cpr.2017.05.004

[36] Ingles CJ, La Greca AM, Marzo JC, Garcia-Lopez LJ, Garcia-Fernandez JM. Social Anxiety Scale for Adolescents: factorial invariance and latent mean differences across gender and age in Spanish adolescents. J Anxiety Disord 2010;24:84755, doi:http://dx.doi.org/10.1016/j.janxdis.2010.06.007.

[37] Bas-Hoogendam JM, van Steenbergen H, van der Wee NJA, Westenberg PM. Relationship between ratings SNPT-R and social anxiety. Database Open Sci Framew 2017, doi:http://dx.doi.org/10.17605/OSF.IO/J58YC.

[38] Mennin DS, Fresco DM, Heimberg RG, Schneier FR, Davies SO, Liebowitz MR. Screening for social anxiety disorder in the clinical setting: using the Liebowitz Social Anxiety Scale. J Anxiety Disord 2002;16:661-73, doi:http://dx.doi.org/ 10.1016/S0887-6185(02)00134-2.

[39] Storch EA, Masia-Warner C, Dent HC, Roberti JW, Fisher PH. Psychometric evaluation of the social anxiety scale for adolescents and the social phobia and anxiety inventory for children: construct validity and normative data. J Anxiety Disord 2004;18:665-79, doi:http://dx.doi.org/10.1016/j. janxdis.2003.09.002.

[40] Jankowski KF, Takahashi H. Cognitive neuroscience of social emotions and implications for psychopathology: examining embarrassment, guilt, envy, and schadenfreude. Psychiatry Clin Neurosci 2014;68:319-36, doi:http://dx.doi. $\operatorname{org} / 10.1111 /$ pcn.12182.

[41] Miller RS. Embarrassment and social anxiety disorder: fraternal twins or distant cousins? In: Hofmann SG, DiBartolo PM, editors. Soc. anxiety clin. dev. soc. perspect.. 3rd ed. Academic Press, Elsevier; 2014. p. 117-40, doi:http://dx. doi.org/10.1016/B978-0-12-394427-6.00005-4

[42] Feinberg M, Willer R, Keltner D. Flustered and faithful: embarrassment as a signal of prosociality. J Pers Soc Psychol 2012;102:81-97, doi:http://dx.doi.org $10.1037 / \mathrm{a} 0025403$.

[43] Miller RS. Is embarrassment a blessing or a curse? In: Tracy JL, Robins RW, Tangney JP, editors. Self-conscious Emot. 1st ed. New York: The Guilford Press 2007. p. 245-62.

[44] Moscovitch DA, Rodebaugh TL, Hesch BD. How awkward! Social anxiety and the perceived consequences of social blunders. Behav Res Ther 2012;50:142-9, doi:http://dx.doi.org/10.1016/j.brat.2011.11.002.

[45] Müller-Pinzler L, Gazzola V, Keysers C, Sommer J, Jansen A, Frässle S, et al. Neural pathways of embarrassment and their modulation by social anxiety. 
Neuroimage 2015;119:252-61, doi:http://dx.doi.org/10.1016/j. neuroimage.2015.06.036.

[46] Boehme S, Miltner WHR, Straube T. Neural correlates of self-focused attention in social anxiety. Soc Cogn Affect Neurosci 2015;10:856-62, doi:http://dx.doi. org/10.1093/scan/nsu128.

[47] Giménez M, Pujol J, Ortiz H, Soriano-Mas C, López-Solà M, Farré M, et al. Altered brain functional connectivity in relation to perception of scrutiny in social anxiety disorder. Psychiatry Res 2012;202:214-23, doi:http://dx.doi. org/10.1016/j.pscychresns.2011.10.008.

[48] Abraham A, Kaufmann C, Redlich R, Hermann A, Stark R, Stevens S, et al. Selfreferential and anxiety-relevant information processing in subclinical social anxiety: an fMRI study. Brain Imaging Behav 2013;7:35-48, doi:http://dx.doi. org/10.1007/s11682-012-9188-X.

[49] Blair KS, Geraci M, Otero M, Majestic C, Odenheimer S, Jacobs M, et al. Atypical modulation of medial prefrontal cortex to self-referential comments in generalized social phobia. Psychiatry Res 2011;193:38-45, doi:http://dx.doi. org/10.1016/j.pscychresns.2010.12.016.

[50] Miers AC, Blöte AW, Bögels SM, Westenberg PM. Interpretation bias and social anxiety in adolescents. J Anxiety Disord 2008;22:1462-71, doi:http://dx.doi. org/10.1016/j.janxdis.2008.02.010.

[51] Kreifelts B, Brück C, Ritter J, Ethofer T, Domin M, Lotze M, et al. They are laughing at me: cerebral mediation of cognitive biases in social anxiety. PLoS One 2014;9:e99815, doi:http://dx.doi.org/10.1371/journal.pone.0099815.

[52] Hirsch CR, Clark DM. Information-processing bias in social phobia. Clin Psychol Rev 2004;24:799-825, doi:http://dx.doi.org/10.1016/j.cpr.2004.07.005.

[53] Clark DM, McManus F. Information processing in social phobia. Biol Psychiatry 2002;51:92-100, doi:http://dx.doi.org/10.1016/S0006-3223(01)01296-3.

[54] Ziv M, Goldin PR, Jazaieri H, Hahn KS, Gross JJ. Is there less to social anxiety than meets the eye? Behavioral and neural responses to three socio-emotional tasks. Biol Mood Anxiety Disord 2013;3:5 10.1186/2045-5380-3-5.

[55] Morrison AS, Heimberg RG. Social anxiety and social anxiety disorder. Annu Rev Clin Psychol 2013;9:249-74, doi:http://dx.doi.org/10.1146/annurevclinpsy-050212-185631.

[56] Antony MM, Purdon CL, Huta V, Swinson RP. Dimensions of perfectionism across the anxiety disorders. Behav Res Ther 1998;36:1143-54, doi:http://dx. doi.org/10.1016/S0005-7967(98)00083-7.

[57] Ashbaugh A, Antony MM, Liss A, Summerfeldt LJ, McCabe RE, Swinson RP. Changes in perfectionism following cognitive-behavioral treatment for social phobia. Depress Anxiety 2007;24:169-77, doi:http://dx.doi.org/10.1002/ da.20219.

[58] Cox SL, Chen J. Perfectionism: a contributor to social anxiety and its cognitive processes. Aust J Psychol 2015;67:231-40, doi:http://dx.doi.org/10.1111/ ajpy.12079.

[59] Newby J, Pitura VA, Penney AM, Klein RG, Flett GL, Hewitt PL. Neuroticism and perfectionism as predictors of social anxiety. Pers Individ Dif 2017;106:263-7, doi:http://dx.doi.org/10.1016/j.paid.2016.10.057.

[60] Cox BJ, Fleet C, Stein MB. Self-criticism and social phob ia in the US national comorbidity survey. J Affect Disord 2004;82:227-34, doi: http://dx.doi.org/10.1016/j.jad.2003.12.012.

[61] Hofmann SG. Cognitive factors that maintain social anxiety disorder: a comprehensive model and its treatment implications. Cogn Behav Ther 2007;36:193-209, doi:http://dx.doi.org/10.1080/16506070701421313.

[62] Haller SPW, Cohen Kadosh K, Scerif G, Lau JYF, Social anxiety disorder in adolescence: how developmental cognitive neuroscience findings may shape understanding and interventions for psychopathology. Dev Cogn Neurosci 2015;13:11-20, doi:http://dx.doi.org/10.1016/j.dcn.2015.02.002.

[63] Dingemans A, van Vliet I, Couvée J, Westenberg H. Characteristics of patients with social phobia and their treatment in specialized clinics for anxiety disorders in the Netherlands. J Affect Disord 2001;65:123-9, doi:http://dx.doi. org/10.1016/S0165-0327(00)00238-X.

[64] Bas-Hoogendam JM, Blackford JU, Brühl AB, Blair KS, van der Wee NJA Westenberg PM. Neurobiological candidate endophenotypes of social anxiety disorder. Neurosci Biobehav Rev 2016;71:362-78, doi:http://dx.doi.org/ 10.1016/j.neubiorev.2016.08.040.

[65] Bas-Hoogendam JM, Harrewijn A, van der Molen MJW, van Steenbergen $H$, van Vliet I, Houwing-Duistermaat J, et al. Profiling endophenotypes in social anxiety disorder: a neurocognitive approach. General background and key question of project. 2014 osf.io/e368 h.

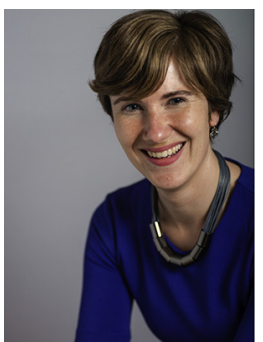

Janna Marie Bas-Hoogendam is a PhD student at Leiden University (Institute of Psychology, Developmental and Educational Psychology) and the Leiden University Medical Center (Department of Psychiatry). She studied Medicine at the Erasmus Medical Center (2003-2007) and obtained her research master's degree in Neuroscience and Cognition at Utrecht University (2009; cum laude). After working at the UMC Utrecht (Department of Psychiatry) and the Cognitive Neuroimaging Lab in Birmingham, she started her PhD-project in 2013. Her work focuses on profiling endophenotypes of social anxiety disorder using structural and functional MRI. Furthermore, she is a coordinator of the ENIGMA-

ANXIETY working group.

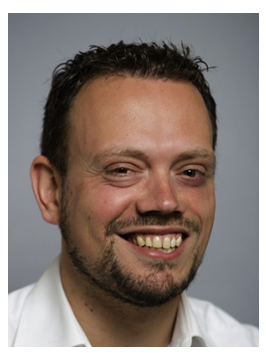

Henk van Steenbergen is an Assistant Professor at the Cognitive Psychology Unit at Leiden University, The Netherlands. Henk studied at Leiden University, where he obtained a BA degree in Philosophy of Psychology, and a BSc and MPhil degree in Cognitive Neuroscience (cum laude) in 2007. He obtained his PhD (cum laude, highest distinction) from Leiden University in 2012. His research focuses on the interactions between emotion, motivation and cognition using a wide variety of behavioral, psychophysiological, and neuroimaging methods.

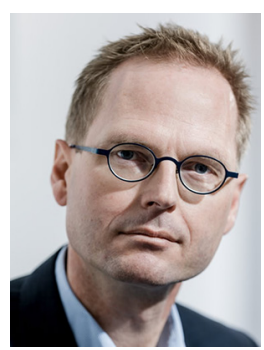

Nic van der Wee is psychiatrist and Full Professor of Biological Psychiatry at Leiden University Medical Center, The Netherlands. He obtained his MD and PhD at the University Medical Center Utrecht, The Netherlands. His group's research focuses on the neurobiology, phenomenology and treatment of stress and trauma-related psychiatric disorders across the life-span, with a special emphasis on the neurobiological mechanism involved in vulnerability and in resilience.

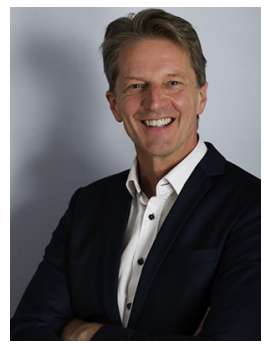

Michiel Westenberg is Full Professor in Developmental Psychology at Leiden University, The Netherlands. He obtained his PhD at Washington University, St. Louis, and was a postdoctoral fellow at the University of California, Berkeley. As PI of the Research Lab Social Anxiety and School Refusal in Adolescence he investigates (a) (a)typical development of social anxiety and the influence of a variety of factors such as increased stress sensitivity during puberty, (b) neurocognitive endophenotypes of social anxiety disorder with a two-generation family design, and (c) clinical protocols for (early) detection and treatment of social anxiety and school refusal among adolescents. 